\title{
Diabetes-free life in India: Application of survival function analysis
}

\author{
Shri Kant Singh, Sarang Pedgaonkar, Parul Puri, Jitendra Gupta \\ International Institute for Population Sciences, Mumbai, India
}

\begin{abstract}
Background: India being a diverse country has an assortment of various socio-economic and demographic structures. These socio-economic and demographic factors often intervene with the diabetes-free survival in any geographical region. The present study explores diabetes-free survival patterns of adult respondents with respect to various socio-economic and demographic factors in eighteen states of India with better demographic indicators.

Material and Methods: The study utilizes data from the fourth round of the District Level Household and Facility Survey (DLHS) undertaken during 2012-2013. The study computes the survival functions by five year age groups followed by Peto and Pike's test for assessing the significant differences in the survival pattern between the various sub-groups in 18 states of India.

Results: The study points out that the diabetes-free survival of a respondent is affected by factors such as the place of residence, sex, social group, the standard of living (wealth) index, and region of residence.

Conclusions: Timely detection, screening, and treatment of non-communicable diseases, as well as palliative care, are recommended to the community for diabetes prevention. A healthy lifestyle including healthy diet, physical activity on regular basis, and avoiding tobacco needs to be promoted.
\end{abstract}

Keywords: Diabetes, non-communicable diseases, Peto and Pike test

Address for correspondence: Parul Puri, International Institute for Population Sciences, Govandi Station Road, Deonar, Mumbai 400088, India.

E-mail: parulpuri93@gmail.com

Received: 12.10.2017, Accepted: 2.12.2017

\section{INTRODUCTION}

Non-communicable diseases (NCDs) account for deaths of 40 million people annually, which is analogous to around 70 percent of all deaths globally. Also, it is responsible for 15 million premature deaths each year between the ages 30 to 69 years, more than 80 percent of which is contributed by low and middle-income countries including India. ${ }^{[1]}$

Being a large country, India presents a substantial assortment of physical features and cultural patterns. It

\begin{tabular}{|l|l|}
\hline \multicolumn{2}{|c|}{ Access this article online } \\
\hline Quick Response Code: & Website: \\
\cline { 1 - 2 } & www.joshd.net \\
\cline { 2 - 3 } & Dol: \\
\hline & Diabetes_36_17 \\
\hline
\end{tabular}

is a land of diversity in terms of religion, caste, language, habitat, socio-economic status, lifestyle, and food habits. ${ }^{[2]}$ In a nutshell, India is "the epitome of the world". Although India has been successful in controlling several infectious and parasitic diseases yet, NCDs are becoming increasingly common, resulting in an enormous burden on the healthcare system. ${ }^{[3]}$ It still finds itself loitering behind other countries on health care outcomes as the response from the government has not been resilient. ${ }^{[4]}$ This is probably due to the large size of the population which generate difficulties for the effective availability

This is an open access journal, and articles are distributed under the terms of the Creative Commons Attribution-NonCommercial-ShareAlike 4.0 License, which allows others to remix, tweak, and build upon the work non-commercially, as long as appropriate credit is given and the new creations are licensed under the identical terms.

For reprints contact: reprints@medknow.com

How to cite this article: Singh SK, Pedgaonkar S, Puri P, Gupta J. Diabetes-free life in India: Application of survival function analysis. J Soc Health Diabetes 2018;6:48-55. 
of health services to all. Diabetes is among the most common chronic NCD affecting both developed and developing countries, including India. ${ }^{[3]}$ Globally, diabetes contributes to around 1.6 million deaths every year. ${ }^{[1]}$ The global prevalence among the population over 18 years of age has risen from 4.7 percent in 1980 to 8.5 percent in 2014. ${ }^{[5]}$ Diabetes is ranked sixth on the global list of causes of death in 2015. ${ }^{[6]}$ Diabetes is fast gaining the status of the potential epidemic with more than 62 million individuals currently suffering from diabetes and more than 77 million suffering from pre-diabetes in India. ${ }^{[7]}$ According to International Diabetes Federation (2015), the prevalence of diabetes in India is predicted to be 109 million by 2035. ${ }^{[8]}$ This higher disease prevalence exerts an enormous economic burden in all parts of the world including India. ${ }^{[3,9]}$ The major challenges posed by diabetes in India are the rising prevalence in urban areas, among young people, delayed diagnoses, low disease awareness among people, limited healthcare facilities, the high cost of disease management, suboptimal diabetes control. ${ }^{[10]}$ The major risk factors involved are high blood pressure, smoking, and physical inactivity. Diabetes being a chronic disease comprises of life-threatening complications along with economic burden to society associated with this disease. ${ }^{[1]}$ Most of the studies in this respect focused on calculating survival function for experimental studies based on follow-up studies using the Kaplan Meier Estimates ${ }^{[12]}$ and thus failed to throw light on the prevalence of a disease in any geographical setup. The present study focuses on computation and comparison of survival functions based on socio-economic and demographic variables by age groups for a cross-sectional data. The main objective of this study is to analyze survival functions by five year age groups and further compare these survival functions for their significance.

\section{MATERIALS AND METHODS}

\section{Data source}

The basic data used in this paper is taken from the fourth round of District Level Household and Facility Survey (DLHS) conducted by the International Institute for Population Sciences (IIPS), Mumbai during 2012-13, under the stewardship of Ministry of Health and Family Welfare (MoHFW), Government of India.

\section{Data availability}

The data is available online on the institute's website and can be easily downloaded. International Institute for Population Sciences was the nodal agency for DLHS-4; being faculty and student here, data has been assessed from the institute's data center.

\section{Ethical approval}

This analysis is based on a secondary data set, where there is no identifiable information on the survey participants. It is worth mentioning that before implementation of DLHS-4, all the survey protocols were approved by the Institute's Ethical Review Board.

The present analysis is concentrated to individuals who have completed 18 years of age and belong to the eighteen states of India with better demographic indicators.

\section{DESCRIPTION OF VARIABLES}

\section{Dependent variables}

The study used the presence of diabetes as the dependent variable for the analysis. A respondent was considered as diabetic if the random blood sugar level was greater than or equal to $140 \mathrm{mg} / \mathrm{dl}^{\left[{ }^{[8]}\right.}$

\section{Independent variables}

Independent variables include socio-economic and demographic characteristics of a respondent like sex (male, female), place of residence (urban, rural), social group (Schedule Caste (SC), /Schedule Tribe (ST), Other Backward Caste (OBC), non-SC/ST and non-OBC), standard of living index (poorest, poorer, middle, richer, richest) and region of residence (Eastern [West Bengal], Western [Maharashtra and Goa], Northern [Himachal Pradesh, Punjab, and Haryana], North-eastern [Sikkim, Arunachal Pradesh, Nagaland, Manipur, Mizoram, Tripura, and Meghalaya], Southern [Andhra Pradesh, Karnataka, Kerala, Tamil Nadu, and Telangana]).

\section{Methodology}

The present study gives the probability of living a diabetes-free life for various five years age groups under the assumption that none of the respondents was found to be diabetic before completing 18 years of age. Following method to obtain survival function with grouped data from a homogeneous population is given below;

Notation

$B_{i}:\left[b_{i-1}, b_{i}\right),(i=1,2, \ldots \ldots \ldots, n)$ is the $i^{\text {th }}$ interval of width $\left(\mathrm{b}_{\mathrm{i}}-\mathrm{b}_{\mathrm{i}-1}\right)$, where $\mathrm{b}_{0}=0$.

$T_{i}$ : number of respondents at the beginning of the interval $\mathrm{B}_{i}$.

$A_{i}$ : number of respondents having diabetes in the interval $\mathrm{B}_{\mathrm{i}}$.

$m_{n}$ : age specific rates of being diabetic of respondents in the $\mathrm{i}$-th interval.

$\mathrm{q}_{\mathrm{i}}$ : estimated conditional probability of completing the age with diabetes during the interval $\mathrm{B}_{\mathrm{i}}$ 
$S_{i}$ : estimate of the probability of diabetes-free life in the interval $B_{i}$.

$f_{i}$ : proportion of respondents who are found to be diabetic at the beginning of interval $\mathrm{B}_{i}$.

The mathematical expression for the above are given below $(\mathrm{n}=5)$,

$$
\begin{gathered}
\mathrm{m}_{\mathrm{i}}=\mathrm{A}_{\mathrm{i}} / \mathrm{T}_{\mathrm{i}}, \\
\mathrm{q}_{\mathrm{i}}=2{ }_{\mathrm{n}} \mathrm{m}_{\mathrm{i}} /\left(2+\mathrm{n}{ }_{\mathrm{n}} \mathrm{m}_{\mathrm{i}}\right), \\
\text { and } \mathrm{p}_{\mathrm{i}}=1-\mathrm{q}_{\mathrm{i}}
\end{gathered}
$$

The survival function $S_{i}$ is estimated by computing the continued products of the $\mathrm{p}_{\mathrm{i}}$ 's. Thus $\mathrm{S}_{1}=\mathrm{p}_{1}, \mathrm{~S}_{2}=\mathrm{p}_{2} \mathrm{p}_{1}$ and so on. We define $\mathrm{p}_{0}=1$, so that we have for $\mathrm{i}^{\text {th }}$ interval $(\mathrm{i}=1,2, \ldots \ldots, \mathrm{n})$

$$
\begin{gathered}
S_{i}=p_{0} p_{1} \ldots \ldots p_{i-1} p_{i}, \quad i=1,2, \ldots \ldots \ldots, n \\
\text { and } f_{i}=S_{i}-S_{i+1}
\end{gathered}
$$

For each time interval, survival probability is calculated as the number of subjects surviving divided by the number of patients at risk. Subjects who have died, are not counted as "at risk" i.e., subjects who are lost are considered "censored" and are not counted in the denominator. Total probability of survival till that time interval is calculated by multiplying all the probabilities of survival at alltime intervals preceding that time (by applying the law of multiplication of probability to calculate cumulative probability).

It is desirable to examine whether there are significant differences among the survival functions belonging to different categories of an independent variable. For this purpose, the hypothesis of no difference between survival functions corresponding to different categories of an independent variable is examined with the help of Peto and Pike's test. A Peto and Pike's test in simple terms is a K- Sample Test of Survival Function. Suppose that we have $\mathrm{k}(\geq 2)$ samples of survival times and the problem is to decide whether they belong to the same population of the survival times. For testing this hypothesis Peto and Pike (1973) proposed a k- sample test, which can be described as follows:

Suppose that in a pooled sample, failures occur at times $\mathrm{t}_{1}<\mathrm{t}_{2}<\mathrm{t}_{3} \ldots .<\mathrm{t}_{\mathrm{n}}$. Let $\mathrm{n}_{\mathrm{ij}}$ be the number of samples in the $\mathrm{j}^{\text {th }}$ sample still at risk prior to $t_{i}$, and let $c_{i j}$ be the number of failure in the $j^{\text {th }}$ sample at time $t_{i}$. Let the corresponding number in the pooled sample be $\mathrm{n}_{\mathrm{i}+}$ and $\mathrm{c}_{\mathrm{i}+}$, respectively $\left(\mathrm{n}_{\mathrm{i}+}=\sum \mathrm{n}_{\mathrm{ij}}\right.$ and $\left.\mathrm{c}_{\mathrm{i}+}=\sum \mathrm{c}_{\mathrm{ij}}\right)$. Under the hypothesis of no difference between samples, the conditionally expected frequency of $c_{i j}$, given $n_{i j}$, can be estimated as $\mathrm{E}_{\mathrm{ij}}=\mathrm{n}_{\mathrm{ij}}\left(\mathrm{c}_{\mathrm{i}+} / \mathrm{n}_{\mathrm{i}+}\right)$. Let $\mathrm{E}_{+\mathrm{j}}=\sum \mathrm{E}_{\mathrm{ij}}$. Then the test statistics suggested by Peto and Pike is:

$$
\sum\left(\mathrm{E}_{+\mathrm{j}}-\mathrm{C}_{+\mathrm{j}}\right)^{2} / \mathrm{E}_{+\mathrm{j}}
$$

which is treated as a Chi-square with $(k-1)$ degree of freedom, $\mathrm{k}$ being the number of samples involved.

All the statistical analysis has been done in MS-Excel and STATA-13 software (Stata Corp, College Station, Texas).

\section{RESULTS}

For illustration, a detailed procedure of getting a survival function is given in the Tables 1(a) and 1(b). Column 1 of these tables show the time interval (age-groups) used for grouping the observations. All the intervals are of length five years and the last one is kept open. The intervals are one-sided closed and one-sided open, that is, if we consider the interval $B_{1}:[18,23)$, this means that the lower limit of the interval is included in $\mathrm{B}_{1}$ but the upper limit is included in $B_{2}$. Column 2 shows the number of respondents found to be diabetic during the $i^{\text {th }}$ time interval. In the table, if we consider the interval $B_{1}$, the number 1607 under $A_{i}$, represents the number of respondents found to be diabetic during the interval $\mathrm{B}_{1}$. In column $3, \mathrm{~T}_{1}=45593$, represents the total number of respondents in the sample. Column 4 gives the age specific rates of being diabetic in the $\mathrm{i}$-th interval. Column 5 gives the conditional probability of being diabetic in the period. The value of $\mathrm{q}_{1}=0.03$, represents that about 3 percent of the total respondent are estimated to suffer with diabetes before completing 23 years of age, provided they have not suffered with diabetes before 18 years of age. Column 6 gives $\mathrm{p}_{\mathrm{i}}=1-\mathrm{q}_{\mathrm{i}}, \mathrm{i}=1,2,3 \ldots, \mathrm{n}$. Thus, $\mathrm{p}_{1}=0.97, \mathrm{p}_{2}=0.96, \mathrm{p}_{3}=0.94$ and so on. Column 7 shows the estimated survival function. From this, we can estimate the probability of being diabetic within first five years of becoming an adult. Thus, here we have made an assumption that initially (till age 18 years) all respondents are found to be living a diabetes-free life. Lastly, column 7 which is denoted by $f_{i}$, shows the probability of getting diabetes in the $\mathrm{i}^{\text {th }}$ interval. It is clear from Table $1(\mathrm{a})$ that chances of becoming diabetic are highest $(8 \%)$ in between the age groups 38 years and 58 years. Also, the probability of living a diabetes- free life shows a declining trend over ages with only 30 percent of the total respondent living without diabetes even after 77 years of age. Survival functions of men and women show a similar pattern [Table 1(a) and 1(b)]. Whereas in age 33 years to 63 years women have a higher probability of surviving without diabetes than men. 
Singh, et al.: Diabetes free life in India

Table 1(a): Pattern of diabetes-free survival (Si) among adult men, DLHS-4, 2012-13

\begin{tabular}{|c|c|c|c|c|c|c|c|}
\hline Age group & $A_{i}$ & $T_{i}$ & $m_{i}=A_{i} / T_{i}$ & $q_{i}$ & $P_{i}=1-q_{i}$ & $S_{i}=P_{0} \cdot P_{1} \ldots P_{i}-1 . P_{i}$ & $f_{i}=S_{i}-S_{i+1}$ \\
\hline$[18-23)$ & 1607 & 45593 & 0.04 & 0.03 & 0.97 & 1.00 & 0.03 \\
\hline [23-28) & 2145 & 42935 & 0.05 & 0.04 & 0.96 & 0.97 & 0.05 \\
\hline$[28-33)$ & 3210 & 43509 & 0.07 & 0.06 & 0.94 & 0.92 & 0.05 \\
\hline$[33-38)$ & 3761 & 37555 & 0.10 & 0.08 & 0.92 & 0.87 & 0.07 \\
\hline$[38-43)$ & 4958 & 39454 & 0.13 & 0.10 & 0.80 & 0.80 & 0.08 \\
\hline$[43-48)$ & 5104 & 32996 & 0.15 & 0.11 & 0.89 & 0.72 & 0.08 \\
\hline$[48-53)$ & 5869 & 32053 & 0.18 & 0.13 & 0.87 & 0.64 & 0.08 \\
\hline$[53-58)$ & 5306 & 25630 & 0.21 & 0.14 & 0.86 & 0.56 & 0.08 \\
\hline$[58-63)$ & 5695 & 25665 & 0.22 & 0.14 & 0.86 & 0.48 & 0.07 \\
\hline$[63-68)$ & 4444 & 18724 & 0.24 & 0.15 & 0.85 & 0.41 & 0.06 \\
\hline$[68-73)$ & 3432 & 13892 & 0.25 & 0.15 & 0.85 & 0.35 & 0.06 \\
\hline$[73-78)$ & 1901 & 7089 & 0.27 & 0.16 & 0.84 & 0.30 & - \\
\hline$[78+)$ & 2092 & 7968 & 0.26 & & & & \\
\hline
\end{tabular}

Table 1(b): Pattern of diabetes-free survival (Si) among adult women, DLHS-4, 2012-13

\begin{tabular}{|c|c|c|c|c|c|c|c|}
\hline Age group & $A_{i}$ & $T_{i}$ & ${ }_{n} m_{i}=A_{i} / T_{i}$ & $q_{i}$ & $P_{i}=1-q_{i}$ & $S_{i}=P_{0} \cdot P_{1} \ldots P_{i}-1 \cdot P_{i}$ & $f_{i}=S_{i}-S_{i+1}$ \\
\hline$[18-23)$ & 2013 & 56345 & 0.04 & 0.03 & 0.97 & 1.00 & 0.03 \\
\hline$[23-28)$ & 2835 & 58942 & 0.05 & 0.04 & 0.96 & 0.97 & 0.04 \\
\hline$[28-33)$ & 3776 & 57682 & 0.07 & 0.06 & 0.94 & 0.93 & 0.06 \\
\hline$[33-38)$ & 4417 & 50152 & 0.09 & 0.07 & 0.93 & 0.87 & 0.06 \\
\hline$[38-43)$ & 5594 & 48614 & 0.12 & 0.09 & 0.91 & 0.81 & 0.07 \\
\hline$[43-48)$ & 5638 & 38321 & 0.15 & 0.11 & 0.89 & 0.74 & 0.08 \\
\hline$[48-53)$ & 7534 & 41136 & 0.18 & 0.13 & 0.87 & 0.66 & 0.08 \\
\hline$[53-58)$ & 6243 & 29240 & 0.21 & 0.14 & 0.86 & 0.58 & 0.08 \\
\hline$[58-63)$ & 6213 & 27093 & 0.23 & 0.15 & 0.85 & 0.50 & 0.08 \\
\hline$[63-68)$ & 4699 & 19146 & 0.25 & 0.15 & 0.85 & 0.42 & 0.06 \\
\hline$[68-73)$ & 3364 & 13605 & 0.25 & 0.15 & 0.85 & 0.36 & 0.06 \\
\hline$[73-78)$ & 1767 & 6412 & 0.28 & 0.16 & 0.84 & 0.30 & - \\
\hline$[78+)$ & 2244 & 8257 & 0.27 & & & & \\
\hline
\end{tabular}

Table 2: Pattern of diabetes free survival among adult respondent by place of residence, DLHS-4, 2012-13

\begin{tabular}{|c|c|c|c|c|}
\hline \multirow{2}{*}{ Age group } & \multicolumn{2}{|c|}{ Urban } & \multicolumn{2}{|c|}{ Rural } \\
\hline & Male & Female & Male & Female \\
\hline$[18-23)$ & 1.00 & 1.00 & 1.00 & 1.00 \\
\hline$[23-28)$ & 0.97 & 0.97 & 0.97 & 0.97 \\
\hline$[28-33)$ & 0.93 & 0.93 & 0.92 & 0.93 \\
\hline [33-38) & 0.87 & 0.87 & 0.87 & 0.87 \\
\hline$[38-43)$ & 0.79 & 0.82 & 0.80 & 0.80 \\
\hline$[43-48)$ & 0.71 & 0.75 & 0.73 & 0.73 \\
\hline$[48-53)$ & 0.62 & 0.67 & 0.65 & 0.64 \\
\hline$[53-58)$ & 0.54 & 0.60 & 0.58 & 0.55 \\
\hline$[58-63)$ & 0.45 & 0.52 & 0.51 & 0.46 \\
\hline$[63-68)$ & 0.38 & 0.45 & 0.44 & 0.39 \\
\hline$[68-73)$ & 0.32 & 0.39 & 0.38 & 0.32 \\
\hline$[73-78)$ & 0.26 & 0.33 & 0.32 & 0.27 \\
\hline
\end{tabular}

The same technique is applied to obtain the survival function with different socio-economic and demographic variables such as place of residence, social group, the standard of living index, and region of residence [Tables 2-5]. About 79 percent of urban men and 82 percent of the urban women survive without diabetes by age 42 years while 80 percent of rural men and 80 percent of rural women live a diabetes-free life by age 42 years. Thus, men from rural areas have higher chances of living diabetes-free life than urban men, however, urban women are at an advantageous position with higher chances of living a diabetes-free life than their rural counterparts.
Also, the probability of surviving without diabetes is highest amongst respondent belonging to Schedule Tribe (ST)/Schedule Caste (SC) followed by respondents from Other Backward Caste (OBC) and is least for respondents from non ST/SC and non OBC category. This gap is clearly visible after 38 years of age and widens as the age of respondent increases [Table 3]. The same pattern is observed for both men and women.

The probability of surviving without diabetes is higher for the poorer category than their middle Socio-Economic Status (SES) group counterparts and a similar pattern is followed for other categories also where lower Socio-Economic Status groups have higher chances of surviving without diabetes. This gap becomes more apparent for respondents over 58 years of age. About 55 percent men in age group [58-63 years) survive without becoming diabetic in poorest class whereas only 50 percent of the respondent from the middle class, 45 percent respondent from richer class, and 43 percent from richest wealth quintiles are able to survive without diabetes. Similarly, about 54 percent women from poorer SES, between ages 58-63 years survive without becoming diabetic whereas only 51 percent of the respondent from the middle class, 47 percent respondent from richer class, and 45 percent from richest wealth 
Table 3: Pattern of diabetes free survival among adult respondent by social group, DLHS-4, 2012-13

\begin{tabular}{|c|c|c|c|c|c|c|}
\hline \multirow{2}{*}{ Age group } & \multicolumn{2}{|c|}{ ST/SC } & \multicolumn{2}{|c|}{ OBC } & \multicolumn{2}{|c|}{ Non-ST/SC and non-OBC } \\
\hline & Male & Female & Male & Female & Male & Female \\
\hline$[18-23)$ & 1.00 & 1.00 & 1.00 & 1.00 & 1.00 & 1.00 \\
\hline$[23-28)$ & 0.97 & 0.97 & 0.97 & 0.97 & 0.97 & 0.96 \\
\hline$[28-33)$ & 0.93 & 0.93 & 0.93 & 0.93 & 0.92 & 0.92 \\
\hline$[33-38)$ & 0.87 & 0.88 & 0.87 & 0.88 & 0.86 & 0.86 \\
\hline$[38-43)$ & 0.81 & 0.82 & 0.80 & 0.82 & 0.78 & 0.79 \\
\hline$[43-48)$ & 0.74 & 0.75 & 0.72 & 0.74 & 0.70 & 0.72 \\
\hline$[48-53)$ & 0.66 & 0.67 & 0.64 & 0.66 & 0.62 & 0.64 \\
\hline$[53-58)$ & 0.58 & 0.60 & 0.56 & 0.57 & 0.53 & 0.55 \\
\hline$[58-63)$ & 0.51 & 0.52 & 0.48 & 0.49 & 0.46 & 0.47 \\
\hline$[63-68)$ & 0.45 & 0.45 & 0.41 & 0.42 & 0.38 & 0.39 \\
\hline [68-73) & 0.39 & 0.39 & 0.34 & 0.36 & 0.32 & 0.33 \\
\hline$[73-78)$ & 0.33 & 0.33 & 0.29 & 0.30 & 0.27 & 0.27 \\
\hline
\end{tabular}

Table 4: Pattern of diabetes free survival among adult respondent by standard of living index, DLHS-4, 2012-13

\begin{tabular}{|c|c|c|c|c|c|c|c|c|c|c|}
\hline \multirow{2}{*}{ Age group } & \multicolumn{2}{|c|}{ Poorest } & \multicolumn{2}{|c|}{ Poorer } & \multicolumn{2}{|c|}{ Middle } & \multicolumn{2}{|c|}{ Richer } & \multicolumn{2}{|c|}{ Richest } \\
\hline & Male & Female & Male & Female & Male & Female & Male & Female & Male & Female \\
\hline$[18-23)$ & 1.00 & 1.00 & 1.00 & 1.00 & 1.00 & 1.00 & 1.00 & 1.00 & 1.00 & 1.00 \\
\hline$[23-28)$ & 0.97 & 0.98 & 0.97 & 0.97 & 0.97 & 0.97 & 0.97 & 0.97 & 0.97 & 0.96 \\
\hline [28-33) & 0.92 & 0.94 & 0.93 & 0.93 & 0.93 & 0.93 & 0.92 & 0.92 & 0.92 & 0.92 \\
\hline [33-38) & 0.89 & 0.89 & 0.88 & 0.88 & 0.87 & 0.88 & 0.86 & 0.87 & 0.85 & 0.86 \\
\hline$[38-43)$ & 0.83 & 0.83 & 0.82 & 0.82 & 0.80 & 0.82 & 0.79 & 0.80 & 0.78 & 0.80 \\
\hline$[43-48)$ & 0.77 & 0.77 & 0.75 & 0.76 & 0.73 & 0.75 & 0.70 & 0.72 & 0.69 & 0.72 \\
\hline$[48-53)$ & 0.69 & 0.69 & 0.67 & 0.68 & 0.65 & 0.67 & 0.62 & 0.64 & 0.60 & 0.63 \\
\hline$[53-58)$ & 0.63 & 0.61 & 0.60 & 0.61 & 0.58 & 0.59 & 0.53 & 0.55 & 0.52 & 0.54 \\
\hline$[58-63)$ & 0.55 & 0.54 & 0.53 & 0.54 & 0.50 & 0.51 & 0.45 & 0.47 & 0.43 & 0.45 \\
\hline [63-68) & 0.49 & 0.48 & 0.46 & 0.47 & 0.43 & 0.44 & 0.38 & 0.39 & 0.36 & 0.37 \\
\hline$[68-73)$ & 0.42 & 0.42 & 0.40 & 0.40 & 0.37 & 0.37 & 0.32 & 0.33 & 0.30 & 0.31 \\
\hline$[73-78)$ & 0.41 & 0.36 & 0.40 & 0.34 & 0.31 & 0.31 & 0.27 & 0.27 & 0.24 & 0.25 \\
\hline
\end{tabular}

Table 5: Pattern of diabetes free survival among adult respondent by region, DLHS-4, 2012-13

\begin{tabular}{|c|c|c|c|c|c|c|c|c|c|c|}
\hline \multirow{2}{*}{ Age group } & \multicolumn{2}{|c|}{ Eastern } & \multicolumn{2}{|c|}{ Western } & \multicolumn{2}{|c|}{ Northern } & \multicolumn{2}{|c|}{ North-eastern } & \multicolumn{2}{|c|}{ Southern } \\
\hline & Male & Female & Male & Female & Male & Female & Male & Female & Male & Female \\
\hline$[18-23)$ & 1.00 & 1.00 & 1.00 & 1.00 & 1.00 & 1.00 & 1.00 & 1.00 & 1.00 & 1.00 \\
\hline$[23-28)$ & 0.96 & 0.95 & 0.96 & 0.96 & 0.96 & 0.96 & 0.97 & 0.97 & 0.98 & 0.98 \\
\hline$[28-33)$ & 0.89 & 0.89 & 0.91 & 0.92 & 0.91 & 0.91 & 0.94 & 0.93 & 0.95 & 0.94 \\
\hline [33-38) & 0.82 & 0.82 & 0.85 & 0.87 & 0.84 & 0.85 & 0.88 & 0.88 & 0.89 & 0.90 \\
\hline$[38-43)$ & 0.74 & 0.74 & 0.78 & 0.80 & 0.76 & 0.78 & 0.83 & 0.83 & 0.83 & 0.84 \\
\hline$[43-48)$ & 0.65 & 0.66 & 0.70 & 0.73 & 0.69 & 0.70 & 0.76 & 0.77 & 0.75 & 0.77 \\
\hline$[48-53)$ & 0.56 & 0.58 & 0.62 & 0.65 & 0.60 & 0.62 & 0.69 & 0.70 & 0.67 & 0.69 \\
\hline$[53-58)$ & 0.48 & 0.50 & 0.54 & 0.57 & 0.52 & 0.53 & 0.62 & 0.63 & 0.58 & 0.60 \\
\hline$[58-63)$ & 0.41 & 0.42 & 0.47 & 0.50 & 0.45 & 0.45 & 0.55 & 0.56 & 0.50 & 0.52 \\
\hline$[63-68)$ & 0.34 & 0.36 & 0.40 & 0.43 & 0.38 & 0.38 & 0.48 & 0.49 & 0.43 & 0.44 \\
\hline$[68-73)$ & 0.28 & 0.30 & 0.34 & 0.36 & 0.32 & 0.32 & 0.43 & 0.43 & 0.37 & 0.38 \\
\hline$[73-78)$ & 0.23 & 0.25 & 0.29 & 0.31 & 0.27 & 0.26 & 0.37 & 0.37 & 0.31 & 0.32 \\
\hline
\end{tabular}

quintiles are able to survive without diabetes. Thus, the probability of surviving without diabetes is higher for lower Socioeconomic Status (SES) group. This finding holds true for both men and women. It is to be taken into consideration that these findings become more distinct when results of poorer and higher classes are taken into consideration.

On having an overall view it is apparently visible that the probability of surviving without diabetes is lowest for the respondents residing in the Eastern region of India, this region is comprised of West Bengal followed by Northern (Himachal Pradesh, Punjab, and Haryana), and Western region (Maharashtra and Goa) of India. The probability of surviving without diabetes is higher among adults from the Southern (Andhra Pradesh, Karnataka, Kerala, Tamil Nadu, and Telangana) and North-eastern (Sikkim, Arunachal Pradesh, Nagaland, Manipur, Mizoram, Tripura, and Meghalaya) regions of the country.

After obtaining these results, it becomes important to test whether these results are statistically true i.e. do these differences actually exist or it is simply because of chance. 
Singh, et al.: Diabetes free life in India

Table 6: Comparison of the diabetes-free survival of women by type of residence DLHS-4, 2012-13

\begin{tabular}{|c|c|c|c|c|c|c|c|c|}
\hline \multirow{2}{*}{ Age group } & \multicolumn{3}{|c|}{ Rural } & \multicolumn{3}{|c|}{ Urban } & \multicolumn{2}{|c|}{ Total } \\
\hline & Oi & ei $=\left(0 i^{\prime} / \mathrm{Ti}^{\prime}\right){ }^{*} \mathrm{Ti}$ & $\mathrm{Ti}$ & Oi & ei $=\left(\mathrm{Oi}^{\prime} / \mathrm{Ti}^{\prime}\right)^{\star} \mathrm{Ti}$ & $\mathrm{Ti}$ & Oi' = Sum(Oi) & Ti' = Sum(Ti) \\
\hline$[18-23)$ & 1219 & 1238 & 34620 & 793 & 774 & 21657 & 2012 & 56278 \\
\hline [23-28) & 1734 & 1710 & 35584 & 1098 & 1122 & 23338 & 2832 & 58922 \\
\hline [28-33) & 2176 & 2251 & 34338 & 1606 & 1532 & 23363 & 3783 & 57701 \\
\hline [33-38) & 2425 & 2591 & 29333 & 2009 & 1844 & 20877 & 4435 & 50210 \\
\hline$[38-43)$ & 3015 & 3278 & 28383 & 2606 & 2343 & 20291 & 5621 & 48674 \\
\hline$[43-48)$ & 2861 & 3291 & 22242 & 2818 & 2388 & 16137 & 5679 & 38379 \\
\hline [48-53) & 4051 & 4543 & 24684 & 3520 & 3028 & 16450 & 7571 & 41134 \\
\hline$[53-58)$ & 3346 & 3775 & 17590 & 2928 & 2499 & 11645 & 6274 & 29235 \\
\hline [58-63) & 3331 & 3839 & 16639 & 2913 & 2405 & 10422 & 6244 & 27061 \\
\hline [63-68) & 2551 & 2922 & 11836 & 2170 & 1798 & 7281 & 4720 & 19117 \\
\hline [68-73) & 1925 & 2108 & 8489 & 1446 & 1264 & 5089 & 3372 & 13578 \\
\hline [73-78) & 973 & 1037 & 3753 & 800 & 737 & 2666 & 1774 & 6419 \\
\hline$[78+)$ & 1318 & 1411 & 5177 & 928 & 835 & 3061 & 2246 & 8239 \\
\hline Total & 30926 & 33995 & 272669 & 25636 & 22567 & 182276 & & \\
\hline
\end{tabular}

For the purpose of comparing these survival functions, Peto and Pike (1973) applied the k-sample test. The complete exercise of implementing Peto and Pike test in case of a place of residence is demonstrated in Table 6 .

It was found that there is a significant difference between the survival functions of women who belong to rural and urban residences $\left[\chi_{\text {Cal }}^{2}=\sum(O i-e i)^{2} / \sum e i=694.39\right.$ but $\left.\chi_{\operatorname{Tab}(1,0.05)}^{2}=3.84\right]$. Similarly, Peto and Pike test is also applied to other independent variables which are taken into consideration. Results obtained from them depicts that diabetes-free survival is affected by sex, caste, wealth $\left[\chi_{\text {Cal }}^{2}=\sum(O i-e i)^{2} / \sum e i=1258.46\right.$ but $\left.\chi_{\text {Tab }(4,0.05)}^{2}=9.49\right]$, and region $\left[\chi_{\text {Cal }}^{2}=\Sigma(O i-e i)^{2} / \sum e i=837.77\right.$ but $\left.\chi_{\operatorname{Tab}(4,0.05)}^{2}=9.49\right]$.

\section{DISCUSSION}

Existing literature confirms a strong genetic predisposition to diabetes among Indians, which easily uncovered under adverse environmental conditions. ${ }^{[2]}$ Studies suggested Asian Indians develop diabetes at younger ages, than other races of the World. ${ }^{[13,14]}$ Studies establish age as a very strong indicator of diabetes in India with the prevalence of diabetes showing a different trend in various age groups. ${ }^{[10]}$ The study provides computation and comparison of diabetes-free survival functions of nationally representative adult sample from eighteen states of India. This study is an improved approach to previous nationwide studies which focused solely on the follow-up cohort data. ${ }^{[6]}$

As diabetes is majorly contributed by lifestyle factors, it becomes immensely important to compare the diabetes-free survival of respondents with the factors such as the place of residence, sex, social group, the standard of living (wealth index), and region of residence, which affects the lifestyle of a respondent. The study points out that the diabetes-free survival of a respondent is affected by factors such as the place of residence, sex, social group, the standard of living (wealth) index, and region of residence.

Male preponderance is clearly visible in some studies, which easily tally with the present study. ${ }^{[1,16]}$ The reason for such difference may be contributed to the genetics of men and women and use of oral pill by women, which may act as a protection against diabetes as pointed out by some studies. ${ }^{[17]}$

As predicted in previous researches, the respondent from rural areas have higher chances of living diabetes-free life than their urban counterparts. ${ }^{[18]}$ Studies speculated that this interaction may have been the result of lifestyle changes such as unhealthy dietary pattern, stress, and sedentary lifestyle as a consequence of urbanization. ${ }^{[19]}$ Currently, nearly three-fourths of the Indian population resides in rural areas, but according to World Health Organization (WHO) estimates it is expected to decrease by nearly 18 percent by the year 2030. This 18 percent of the population would be added to the urban areas. ${ }^{[20]}$ Thus, in future, the rural areas presently under transition of urbanization could emerge as pockets of increased prevalence of diabetes in India.

The rise in the prevalence level of diabetes can be linked to the factors such as dietary and lifestyle changes which are brought about by the transition to a sedentary lifestyle contributed by an increased level of wealth. ${ }^{[21]}$ Similar findings are also set by the present study where the respondents from lower wealth quintile are more prone to survive without diabetes as compared to their higher wealth quintile counterparts.

White rice is an essential part of food amongst people residing in West Bengal. Existing literature suggests an association 
between consumption of white rice and risk of diabetes in Indian population. ${ }^{[16]}$ Thus, having an overall view it is apparently visible that the probability of surviving without diabetes is lowest for the respondents residing in the Eastern region of India, which comprises of West Bengal followed by Northern (Himachal Pradesh, Punjab, and Haryana) attributing to high level of abdominal obesity in this region, ${ }^{[22]}$ and Western region (Maharashtra and Goa) which can be attributed to high level of fat intake in the diet. ${ }^{[16]}$

The probability of surviving without diabetes is higher for Southern (Andhra Pradesh, Karnataka, Kerala, Tamil Nadu, and Telangana) and North-eastern (Sikkim, Arunachal Pradesh, Nagaland, Manipur, Mizoram, Tripura, and Meghalaya) regions of India. The variations observed in the prevalence of diabetes are largely contributed by diversity in terms of diet, physical activity, urbanization, and some unknown social factors.

\section{CONCLUSIONS}

The findings of this study underline the ongoing epidemiological transition in India and help to understand the progression of diabetes in population across various background characteristics and also highlight the increasing burden of diabetes in India. The probability of surviving without diabetes is particularly less among men than women, among those residing in urban areas, and those belonging to upper social and economic classes. It is evident from the pattern of distribution of diabetes-free survival that the major determinants of progression of the diabetes epidemic in India are urbanization and betterment of economic status. The diabetes-free survivor is particularly reduced in population groups which are experiencing the resultant changes in lifestyle in terms of unhealthy dietary pattern and physical inactivity. This study also emphasizes the relatively earlier age at which the significant reduction in diabetes-free survival is taking place in India and the agglomeration of diabetes in older age groups. With the increase in life expectancy and ongoing urbanization, there will be a tremendous increase in the burden of diabetes in India.

\section{RECOMMENDATIONS}

The current scenario of diabetes in India warrants a timely response to prevailing risk factors and determinants of diabetes like appropriate changes in lifestyle, dietary pattern and physical activities to prevent the occurrence of diabetes. It is necessary to disseminate the knowledge and create awareness about diabetes, its determinants and associated complications among people. At the same time efforts need to be directed towards bolstering of health services so that services for screening, timely diagnosis and adequate treatment, and palliative care for diabetes is available to people who are already suffering from it and complications of diabetes are avoided.

\section{LIMITATIONS}

The assumption that none of the respondents would be affected by diabetes before the age of 18 years may not hold true in some cases.

\section{Acknowledgement}

Authors are thankful to all the project coordinators of DLHS-4 for their relentless efforts in producing such a vital information for community-based estimates of the prevalence of diabetes.

\section{Previous presentations}

None.

\section{Contribution details}

SKS apprehended the idea. SKS and JG designed the experiment and analyzed it. SKS, SP, and PP interpreted the results and drafted the manuscript. All the authors take responsibility for the integrity of the work as a whole from inception to published article. SKS would be the guarantor.

\section{Statement of approval}

All the authors read and approved the final manuscript. Also, the requirements for authorship as stated have been met, and each author believes that the manuscript represents honest work.

\section{Financial support and sponsorship}

Nil.

\section{Conflicts of interest}

There are no conflicts of interest.

\section{REFERENCES}

1. W.H.O. Diabetes [Internet]. 2017 [cited 15 August 2017]. Available from http:s//www.who.int/mediacentre/factsheets/fs312/en/

2. Ramachandran A, Snehalatha C. Current scenario of diabetes in india. J Diabetes 2009;1:18-28.

3. Yadav S, Arokiasamy P. Understanding epidemiological transition in india. Glob Health Action 2014;7:23248.

4. Bansode B, Nagarajan R. Diabetes: A review of awareness, comorbidities, and quality of life in India. J Soc Health Diabetes 2017;5:77.

5. Mathers CD, Loncar D. Projections of global mortality and burden of disease from 2002 to 2030. Plos Med 2006;3:e442.

6. Joshi SR, Parikh RM. India-diabetes capital of the world: Now heading towards hypertension. J Assoc Physicians India 2007;55:323-4. 
7. Rekha S. Assessment of glycemic status and expenditure incurred in diabetic subjects in urban field practice area of kempegowda institute of medical sciences, bangalore (Doctoral dissertation).

8. International Diabetes Federation. IDF diabetes atlas. 7 th ed. Brussels: International Diabetes Federation; 2015.

9. Yesudian CA, Grepstad M, Visintin E, Ferrario A. The economic burden of diabetes in india: A review of the literature. Global Health 2014;10:80.

10. Ramachandran A, Mary S, Yamuna A, Murugesan N, Snehalatha C. High prevalence of diabetes and cardiovascular risk factors associated with urbanization in india. Diabetes Care 2008;31:893-8.

11. Yesudian CA, Grepstad M, Visintin E, Ferrario A. The economic burden of diabetes in india: A review of the literature. Global Health 2014;10:80.

12. Goel MK, Khanna P, Kishore J. Understanding survival analysis: Kaplan-Meier estimate. Int J Ayurveda Res 2010;1:274-8.

13. Ramachandran A, Snehalatha C, Vijay V. Low risk threshold for acquired diabetogenic factors in asian indians. Diabetes Res Clin Pract 2004;65:189-95.

14. Decode-Decoda Study Group, European Diabetes Epidemiology Group. Age, body mass index and type 2 diabetes-associations modified by ethnicity. Diabetologia 2003;46:1063-70.

15. Anjana RM, Pradeepa R, Deepa M, Datta M, Sudha V, Unnikrishnan R, et al.; ICMR-INDIAB Collaborative Study Group. Prevalence of diabetes and prediabetes (impaired fasting glucose and/or impaired glucose tolerance) in urban and rural india: phase I results of the indian council of medical research-india diabetes (ICMR-INDIAB) study. Diabetologia 2011;54:3022-7.

16. Meshram II, Vishnu Vardhana Rao M, Sudershan Rao V, Laxmaiah A, Polasa K. Regional variation in the prevalence of overweight/obesity, hypertension and diabetes and their correlates among the adult rural population in india. Br J Nutr 2016;115:1265-72.

17. Gale EA, Gillespie KM. Diabetes and gender. Diabetologia 2001;44: 3-15.

18. Ajay VS, Prabhakaran D, Jeemon P, Thankappan KR, Mohan V, Ramakrishnan L, et al. Prevalence and determinants of diabetes mellitus in the indian industrial population. Diabet Med 2008;25:1187-94.

19. Bhargava SK, Sachdev HS, Fall CH, Osmond C, Lakshmy R, Barker DJ, et al. Relation of serial changes in childhood body-mass index to impaired glucose tolerance in young adulthood. N Engl J Med 2004;350:865-75.

20. Petersen PE. The world oral health report 2003: continuous improvement of oral health in the 21 st century-the approach of the WHO global oral health programme. Community Dent Oral Epidemiol 2003;31(Suppl 1):3-23.

21. Klautzer L, Becker J, Mattke S. The curse of wealth - middle eastern countries need to address the rapidly rising burden of diabetes. Int J Health Policy Manag 2014;2:109-14.

22. Tripathy JP, Thakur JS, Jeet G, Chawla S, Jain S, Pal A, et al. Prevalence and risk factors of diabetes in a large community-based study in north india: results from a STEPS survey in punjab, india. Diabetol Metab Syndr 2017;9:8. 